\title{
Analysis of the Elemental Composition of the Artefacts from the Kosewo Archaeological Site
}

\author{
A.M. GÓJSKA* AND E.A. MiśtA \\ National Centre for Nuclear Research, A. Sołtana 7, 05-400 Otwock, Poland \\ (Received April 6, 2016)
}

\begin{abstract}
The Migration Period on the present Polish territories is considered as a time of depopulation of Oder, Warta, and Vistula basins. The prerequisite for such assumption is lack of the archaeological finds in these regions. In contrast, on the Mragowo Lake District and in the Lyna basin, one can find wealth of burial crematory equipped with items from the Roman period and made in the Germanic style. The analyses using the physics techniques gives an opportunity to the meeting of history with the contemporary times and the lost things may see the light of present day. The discovered artefacts may constitute a source of knowledge, which, after analysis, will be able to fill the gaps on the map of settlements in the Polish territories. The energy-dispersive X-ray fluorescence system was used to analyze the set of Polish archaeological artefacts found in an excavation in Masurian Lakes District. The compact X-ray tube developed in the National Centre for Nuclear Research (NCBJ) was used as an $\mathrm{X}$-ray source in the system designed for the energy-dispersive X-ray fluorescence studies. The X-ray fluorescence spectra of the artefacts were registered with the Amptek SDD spectrometer and the concentrations of elements were determined. The measurements show that the X-ray system developed in NCBJ with transmission type X-ray tube and the Amptek SDD spectrometer is an effective tool for chemical composition analyses of archaeological objects and can be successfully applied in archaeometry.
\end{abstract}

DOI: 10.12693/APhysPolA.130.1415

PACS/topics: 81.05.Bx, 82.80.Ej, 82.80.Dx, 82.80.Ms, 82.80.Pv

\section{Introduction}

The Migration Period dated to AD 480-550 induces many polemics among archaeologists studying the prehistoric times of the Polish lands. Research on problems of contacts of that areas covers the influence of the Roman provincial culture which can play an important role in clarifying issues related to the times of the Migrations Period in Poland. In the middle of the fifth century there was a radical change in the situation of the settler-culture on Polish territory. As a result of leaving the population of residential areas and small stabilization of settlement in the late phase of the Migration Period, as well as a result of the spreading of new forms of ritual burial, there is a problem with serious poverty of archaeological material from that period. Nevertheless, the Masurian Lake District in the south-western part of the Mragowo Lake District is rich in crematory cemeteries with burials equipped with pottery and ornaments continuing local traditional style of the Roman period. The brooches, parts of the belts and bracelets found in Masuria represent interregional Germanic style of the late Migration Period. The culture group related to fusion of local and foreign influences as well as the Germanic traditions, originally was given name Masurgermanische Kultur [1-3] and after World War II it was named the Olsztyn group [4] and is classified as the Western Baltic culture. The Olsztyn group occupies a unique place on the map of archaeological cultures of Central Europe. During all the turbulent transformation of the V, VI and VII centuries

\footnotetext{
*corresponding author; e-mail: aneta.gojska@ncbj.gov.pl
}

it is characterized by stable settlement and unique wealth coming from multidirectional European trade relations. Thus the unique sepulchral complex Kosewo has become an important part of the archaeological studies.

Archaeology as a scientific discipline incorporates use of methodological workshops of various fields of science. The analysis of antique objects made from metal alloys is an area of interest of archaeometallurgy, dedicated to the research related to finding the origin of the raw material alloy and technological processes and also the degradation problem resulting from corrosion of the object, which directly influences in restoration works.

A most useful research method used in material composition determination is the X-ray fluorescence (XRF). The elemental composition of the studied material can be identified basing on X-ray emission of specific elements. The concentration of a specific element can be determined using the relationship between the intensity of characteristic X-ray and the concentration of the element in the sample. The determination of the elemental composition of material is one of the primary interests from the archaeological point of view. Thus, the analytical X-ray spectrometry techniques are often used in the art and cultural heritage research [5-9].

Since the XRF method is non-destructive, it gives, among others, an opportunity to analyze archaeological artefacts composition. The analysis of elemental composition of artefacts studied can give important information about mines $[10,11]$ and a mint technique [12] in the interest region at specific time. A large number of researches has been performed using various radiation sources as well as various techniques involving the XRF. The X-ray tubes $[13,14]$ as well as radioactive 
sources such as americium $\left({ }^{241} \mathrm{Am}\right)$ [5] and plutonium $\left({ }^{238} \mathrm{Pu}\right)$ [15] were used to excite X-ray fluorescence.

The aim of this research was to check the usefulness of the novel energy dispersive XRF (ED-XRF) system which contains the compact transmission X-ray tube with silver anode and the Amptek SDD spectrometer. The ED-XRF system was used for the first time in elemental composition analysis of selected artefacts from the archaeological site in Kosewo (administrative district of Gmina Mrągowo in northern Poland).

\section{Method and materials}

\subsection{ED-XRF system and measurements}

The ED-XRF system presented in this paper has been used to study X-ray spectra of selected archaeological artefacts dated to the Migration Period, which is referred to the Middle Iron Age. Each sample under study has undergone irradiation induced by X-ray tube. The X-ray radiation from the $\mathrm{X}$-ray tube can lead to the ionization of $K$-shell or $L$-shell of elements in a specific sample. The electron transition from higher shell $(L$ or $M)$ fills the hole in the $K$-shell and initiates the $K_{\alpha}$ and $K_{\beta}$ (or $L_{\alpha}, L_{\beta}$ ) transitions that can be observed in spectra as characteristic X-ray lines. Each element has its own specific transition energy. Thus, the characteristic lines of the X-ray spectrum constitute a signature of the specific element in the studied object. The energy and intensity of the X-ray transitions can be accurately determined by the X-ray spectroscopic method.

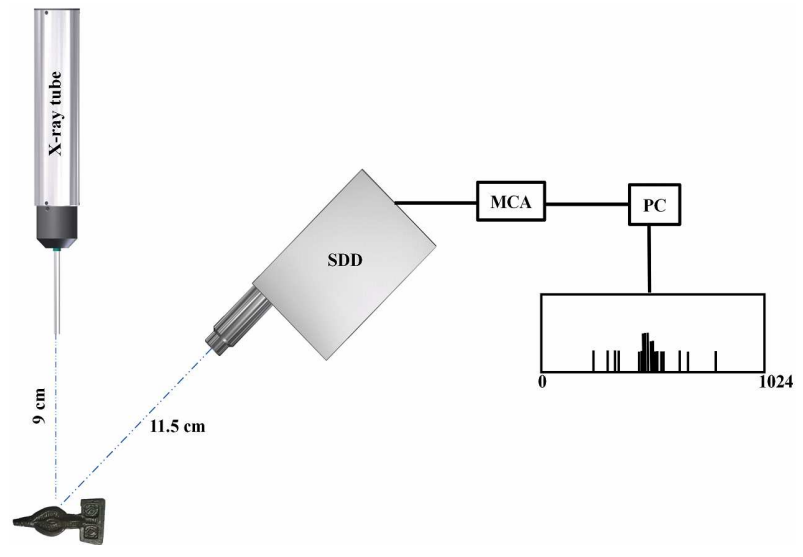

Fig. 1. Experimental setup of the XRF system.

In the XRF measurements the X-ray generator designed and built in the National Centre for Nuclear Research (NCBJ) in Świerk, Poland was used. The compact X-ray generator was constructed within the transmission X-ray tube technology. The generator consists of two subassemblies: electronics (power supply control unit) and X-ray tube. The X-ray generator is compact with the weight of $0.835 \mathrm{~kg}$ and length of $430 \mathrm{~mm}$. Diameter of the power supply-control unit is $55 \mathrm{~mm}$. The anode component is $190 \mathrm{~mm}$ long with the diameter of $8 \mathrm{~mm}$, while the target diameter is $5 \mathrm{~mm}$. The power supply control unit is powered by an external power supply of $12 \mathrm{~V}_{D C}$ and load up to $1 \mathrm{~A}$. The accelerating voltage and the beam current can be continuously adjusted. The maximum voltage is $50 \mathrm{kV}$. The focused electron beam hits the anode silver target sputtered on beryllium and X-ray radiation is generated. The system was designed to irradiate the $2.1 \mathrm{~cm}^{2}$ of studied surface. There can be obtained in that way the average value of the elemental composition. We believe that this may be an important advantage in comparison with other commercially available XRF systems which can irradiate only a very small part of the studied sample. The X-ray generator was operated with anode voltage and current equal to $40 \mathrm{kV}$ and $30 \mu \mathrm{A}$, respectively. The fluorescence spectra of artefacts were registered with SDD detector. The energy resolution of the Amptek detector was previously assumed to be $149 \mathrm{eV}$ at $5.9 \mathrm{keV}$ photon energy. Whereas the measured energy resolution at $5.9 \mathrm{keV}$ was found to be $152.9 \pm 0.3 \mathrm{eV}$. The distances between X-ray source and measured object ( $\mathrm{SO}$ ) and between objects and detector (OD) were set to $9 \mathrm{~cm}$ and $11.5 \mathrm{~cm}$, respectively (Fig. 1). The energy spectra were analyzed by the Amptek ADMCA multi-channel analyzer. The summary of the experimental system is shown in Table I.

TABLE I

Experimental system of performances.

\begin{tabular}{c|c}
\hline \hline X-ray tube type & transmission \\
anode of X-ray tube & $\mathrm{Ag}$ \\
HV & $40 \mathrm{kV}$ \\
anode current & $30 \mu \mathrm{A}$ \\
detector & $\mathrm{SDD} 25 \mathrm{~mm}^{2}$ \\
source-object distance (SO) & $9 \mathrm{~cm}$ \\
object-detector distance (OD) & $11.5 \mathrm{~cm}$ \\
incident angle & $90^{\circ}$ \\
detector angle & $45^{\circ}$ \\
irradiated area & $2.1 \mathrm{~cm}^{2}$
\end{tabular}

Before the measurements of the artefacts with X-ray tube, the detector was energetically calibrated by use of the radioisotope sources: ${ }^{55} \mathrm{Fe}: 5.9 \mathrm{keV}\left(\mathrm{Mn} K_{\alpha}\right)$ and $6.5 \mathrm{keV}\left(\mathrm{Mn} K_{\beta}\right) ;{ }^{109} \mathrm{Cd}: 22.1 \mathrm{keV}\left(\mathrm{Ag} K_{\alpha}\right)$ and $24.9 \mathrm{keV}$ $\left(\operatorname{Ag} K_{\beta}\right) ;{ }^{137} \mathrm{Cs}: 32 \mathrm{keV}\left(\mathrm{Ba} K_{\alpha}\right)$. The good linearity in the energy calibration was found in the whole X-ray energy range applicable for our studies $(8-25 \mathrm{keV})$. The linear fit of energy calibration was made with $\chi^{2}=0.999$.

\subsection{Archaeological artefacts}

The composition of 9 bronze objects, found in cremation cemetery in the Masurian Lakes District, dated to the Migration Period were investigated. There are fragments of bracelet and fibulae among them (Fig. 2). The previous studies on the fibulae which were found in other archaeological sites in Masuria showed that the brooches bear witness to foreign styles, whereas most of the plate fibulae, including in particular the specimens of bronze, were made at the Masurian Lake District [16]. 


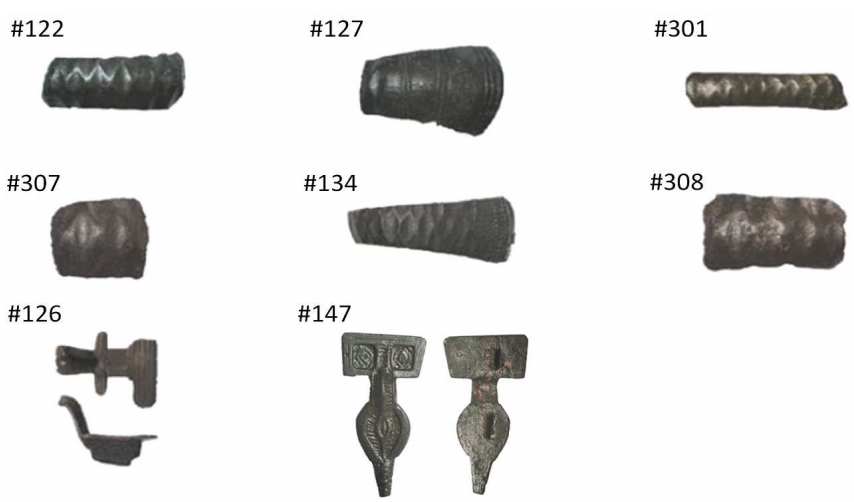

Fig. 2. Bronze bracelets numbered \#122 and \#127, middle \#301 and \#307, down \#134 and \#308 and bronze fibulae numbered \#126 and \#147.

Since the archaeological site Kosewo is dated to the Migration Period it was assumed that the ancient metallurgists probably used the melting technique in metal art production. The basic technique of manufacturing of metal products was casting which consists in pouring molten raw material into appropriate mould to obtain desired shape.

Analysis of plate fibulae indicate that they were probably made by casting into a clay mould. The bracelets were probably forged by use of cast rod or ingot. The intermediate products were then shaped with use of various types of punches and hammers [17].

There should considered in chemical analysis the presence of alloy dopants used in order to give such properties of the alloy like ductility, malleability, and strength, which allowed for metallurgical processing (milling, forging, and casting) $[18,19]$. Corrosion degradation due to soil deposition over the years could influence the composition of the artefacts found. According to the character of the archaeological site all the objects demonstrate morphological changes caused by secondary heat treatment associated with burning at the stake. Moreover, the set of the bracelets pieces of found together suggests that they might had originally constituted one object.

\section{Results and discussion}

Figures 3 and 4 show the XRF spectra of artefacts after background subtraction. The background subtraction was made as follows: the XRF spectra of artefacts were measured during $t=120 \mathrm{~s}$, then the background spectra (without artefacts) were collected during the same time. Finally, the background spectra were subtracted from the artefacts XRF spectra using the ADMCA software. The spectra were analyzed using the XRF-FP software (X-ray fluorescence - energy dispersive spectrometry - fundamental parameter program). The first step was the elemental identification and Gaussian smoothing of each channel in spectrum. The next step was the peak intensities extraction by integration of counts for defined region of interest (ROI) of studied peak. The overlappings of peaks are corrected by Gaussian deconvolution.
The $\mathrm{Ag} K_{\alpha}(22.1 \mathrm{keV})$ and $\mathrm{Cu} K_{\alpha}(8.04 \mathrm{keV})$ characteristic lines were fitted using Gaussian profile. Because it is not possible to separate the pattern lines, the overlapped lines were taken into account $\left(K_{\alpha}=K_{\alpha_{1}}+K_{\alpha_{2}}\right.$, $\left.K_{\beta}=K_{\beta_{1}}+K_{\beta_{3}}\right)$. The composition analysis consists in the conversion of peak intensities to concentrations of elements. The conversion is made by using of implemented database in the XRF-FP software.

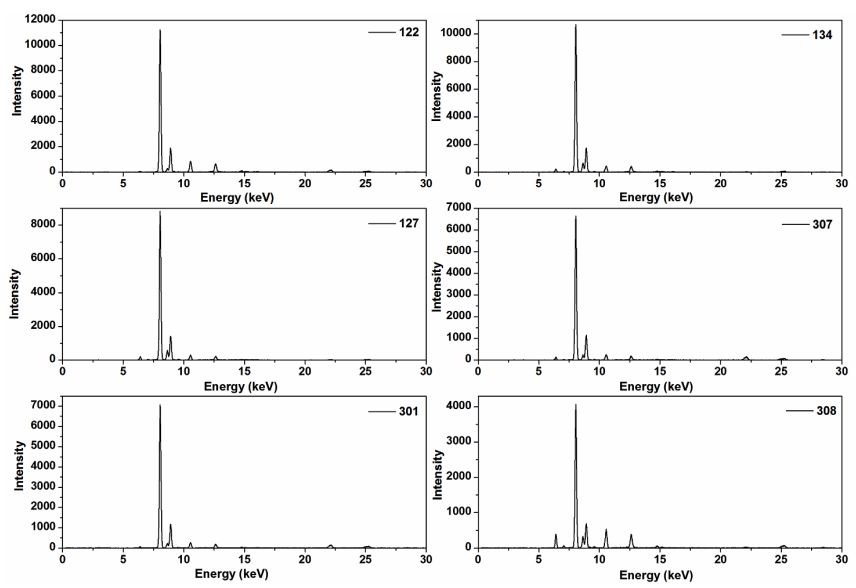

Fig. 3. Measured XRF spectra of bracelet.

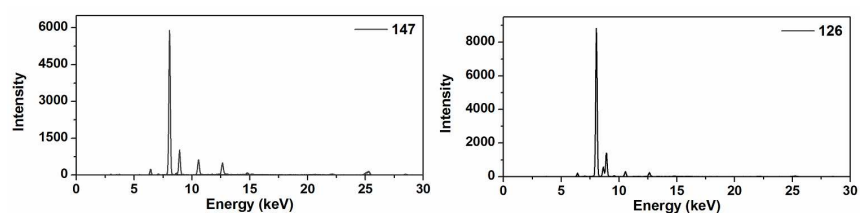

Fig. 4. Measured XRF spectra of fibulae.

The results of the analyses performed on the studied artefacts indicated that almost all of them are made of copper (with concentration of $77.2 \%-81.8 \%$ ), lead $(7.7 \%-8.1 \%)$ and tin $(1.5 \%-4.4 \%)$ with silver, zinc, iron, palladium, and gold impurities. The bracelets \#301 and \#307 seems to be made from the same material containing almost identical concentration of $\mathrm{Cu}, \mathrm{Pb}, \mathrm{Ag}$, and Sn. This can confirm the hypothesis that they might had originally constituted one item. The bracelet \#308 and fibulae \#147 have quite different composition, in comparison to other artefacts, with relatively low content of $\mathrm{Cu}$ and high concentration of $\mathrm{Pb}$. The bracelet \#308 is only one artefact with tin and iron content of $14.2 \%$ and $4.9 \%$, respectively.

The analyses indicate that studied artefacts can be marked as a products made of tin-lead bronzes or lead bronzes. The deviation from the modern bronzes can be explained as the result of use of non-purified raw materials and the uncontrolled mixing arising solely from the experience of the ancient metallurgist. The presence of silver as well as traces elements such as indium and palladium occurring in the silver ore deposits may confirm the use of silvering or melting raw material containing these components. Silvering is a technique consisting in coating 
of the objects made of metal, mostly copper alloys, with a thin silver layer. The artefacts finished in this way had to imitate items made from noble metal. The ancient bronze items are mostly low-tin bronzes $(\mathrm{Sn}<17 \%)$, and many of them are leaded $[18,20]$. The traces visible in analysis of the artefacts from Kosewo indicate that most likely the ancient metallurgists used the amalgam coating technique. This technique consists in dissolving the noble metal in mercury. As a result of high temperature mercury evaporates leaving a thin layer of noble metal on the surface of an ornament item. Some amounts of zinc and silver can be explained by the fact that the silver layer could have been removed during the process of degradation in soil induced by heat influence during body burning.

The quantitative analytical results (with $10 \%$ error) are shown in Table II. As trace elements there were considered the elements which are detectable but not quantified (less than 1\%).

TABLE II

Elemental concentrations determined using XRF-FP software.

\begin{tabular}{c|c|c|c|c|c|c|c|c|c}
\hline \hline & \multicolumn{7}{|c}{ Elemental concentration [wt\%] } \\
\cline { 2 - 9 } Element & $\# 122$ & $\# 127$ & $\# 134$ & $\# 301$ & $\# 307$ & $\# 308$ & $\# 126$ & $\# 147$ \\
\hline $\mathrm{Cu}$ & 77.2 & 81.8 & 80.3 & 62.1 & 60.5 & 43.5 & 77.7 & 50.4 \\
$\mathrm{Ag}$ & 6.3 & 3.1 & trace & 13.2 & 13.8 & 3.7 & 1.1 & 13.4 \\
$\mathrm{~Pb}$ & 7.7 & 9.3 & 8.1 & 12.2 & 12.1 & 27.8 & 10.3 & 22.6 \\
$\mathrm{Zn}$ & 2 & 2.4 & 5.2 & 2.2 & 2.3 & 3.6 & 4.9 & 2.2 \\
$\mathrm{Sn}$ & 4.4 & 1.5 & 2.5 & 7.5 & 7.4 & 14.2 & 2.4 & 6.4 \\
$\mathrm{Fe}$ & trace & trace & 1.6 & trace & 1.4 & 4.9 & 1.5 & 2.9 \\
$\mathrm{Pd}$ & trace & trace & trace & trace & trace & trace & trace & trace \\
$\mathrm{Au}$ & trace & trace & trace & trace & trace & trace & trace & trace \\
$\mathrm{In}$ & trace & trace & trace & trace & trace & trace & trace & trace
\end{tabular}

\section{Conclusions}

The crematory cemetery with visible remains of funeral pyre and with burned human remains was uncovered in 2014. The form of the land on which the cemetery was located carried visible signs of advanced erosion, especially in the deep furrows of plowed forest.

There have been found fragments of metal ornaments like bracelets and fibulae in violated litter. Bronze bracelets were the most popular decoration throughout the Migration Period therefore they are items mostly discovered in the archaeological sites. Brooch, also called fibula, is the most popular relict discovered by archaeologists at graveyards and bears the stamp of the periods of influence of Romans and Migration. The often changing characteristic shapes and ornaments, depending on the current fashion, are the best indicator allowing to estimate burials dates [21, 22]. This unique relict was a combination of utilitarian function such as clothing clasp and a decorative one. Fibulae probably were not worn every day, but only on special occasions on complement ceremonial costume. Fibulae and other metal costume elements and everyday use objects, were placed together with the deceased on the funeral stack. During the Migration Period, in the ritual cremation, they were placed together with the burned remains in the tombs. Many of them carry signs of a strong burnout or had completely melted, which significantly impedes their identification. Nevertheless, on the base of research of a small piece, the reconstruction of original form becomes possible. Thus the artefacts studied can be qualified to the appropriate type.

The assembly composed of the X-ray tube developed in the NCBJ and the SDD spectrometer was used to perform a basic test of a system for archaeological studies. The measurements indicated that the compact X-ray generator developed in NCBJ can be applied to XRF research with operating parameters of voltage of $40 \mathrm{kV}$ and current of $30 \mu \mathrm{A}$.

The compact and safe in use ED-XRF system presented in this paper collects data from the $2.1 \mathrm{~cm}^{2}$ of surface of the tested material and can be used in archaeometry to obtain an average value of any element concentration in entire artefact. Thus we believe that it is an effective tool for chemical composition analyses of archaeological finds.

\section{Acknowledgments}

This scientific work was supported by the project of DAJNA Foundation and Ministry of Culture and National Heritage. The authors are grateful to Marek Kowalski for providing language help.

\section{References}

[1] N. Aberg, East Prussia in the Migration Period,, Uppsala 1919, p. 70 (in German).

[2] C. Engel, The secret of the Masurian culture, Masurischer Volkskalender Allenstein, 1938, p. 39 (in German).

[3] E. Šturms, Archaeol. Geograph. 1, 20 (1950).

[4] J. Okulicz, Prehistory of Prussia from the late Paleolithic to the VII Century AD, Ossolineum, Wrocław 1973, p. 476.

[5] M. Mantler, M. Schreiner, X-Ray Spectrom. 29, 3 (2000).

[6] M.S. Shackley [ed.], in: Archaeology X-Ray Fluorescence Spectrometry (XRF) in Geoarchaeology, Springer Science + Business Media, LLC, 2011, New York.

[7] M. Schreiner, B. Frühmann D. Jembrih-Simbürger, R. Linke, Adv. X-ray Anal. 47, 1 (2004).

[8] N.A. Shugar, L.J. Mass, Studies in Archaeological Science. Handheld XRF for Art and Archaeology, Leuven University Press, Leuven 2012.

[9] M. Uda, G. Demortier, I. Nakai, X-Rays for Archaeology, Springer, Dordrecht, 2005.

[10] B. Sodaei, P. Masjedi Khak, M. Khazaie, Interdisciplin. Archaeol. 2, 211 (2013). 
[11] M. Baldassarri, G. de Holanda Cavalcanti, M. Ferretti, A. Gorghinian, E. Grifoni, S. Legnaioli, G. Lorenzetti, S. Pagnotta, L. Marras, E. Violano, M. Lezzerini, V. Palleschi, J. Archaeol. 2014, 519218 (2014).

[12] B. Constantinescu, R. Bugoi, E. OberländerTârnoveanu, K. Pârvan, Roman. Rep. Phys. 57, 1021 (2005).

[13] S.A. Abd El Aal, W.A. Ghaly, H.T. Mohsen, A. El Falaky, A.I. Helal, Int. J. Pure Appl. Phys. 8, 69 (2012).

[14] B. Miazga, Eston. J. Archaeol. 18, 57 (2014).

[15] P.S. Parreira, C.R. Appoloni, R.M. Lobo Vieira, R.B. Scorzelli, L. Le Corre, M.F. Guerra, ArcheoSciences 33, 313 (2009).

[16] V. Hilberg, Jahrbuch der Bodendenkmalpflege in Mecklenburg-Vorpommern 51, 295 (2003) (in German).
[17] DAJNA Foundation, private communication.

[18] D. Ashkenazi, N. Iddan, O. Tal, Archaeometry 54, 528 (2012).

[19] P. Valerio, R.J.C. Silva, A.M. Monge Soares, M.F. Araujo, F.M. Braz Fernandes, A.C. Silva, L. Berrocal-Rangel, J. Archaeol. Sci. 37, 1811 (2010).

[20] D.A. Scott, Metallography and Microstructure of Ancient and Historic Metals, The Getty Conservation Institute and Archetype Books, Singapore 1991.

[21] O. Almgren, Studies on northern European fibula of the early centuries $C E$, Mannus Bibliothek, Leipzig 1923 (in German).

[22] J. Kostrzewski, The East Germanic culture of the late La Tene, Mannus Bibliothek, Vol. 18, Leipzig 1919 (in German). 